\title{
FORMAÇÃO E IDENTIDADE DE PROFESSORES DE LÍNGUAS (ESTRANGEIRAS)
}

\author{
Gabriela Quatrin Marzari
}

\section{RESUMO}

Este trabalho apresenta uma discussão sobre a formação de professores de Línguas (Estrangeiras) (primeira parte) e as representações de professores de Inglês como Língua Estrangeira (ILE) sobre suas identidades profissionais (segunda parte). Sobre a formação pré-serviço especificamente, atento para o conseqüente despreparo desses profissionais frente às exigências de eventuais contextos de atuação, explicitando as origens desse problema e algumas estratégias para superá-lo. Três aspectos considerados preponderantes à formação pré-serviço de professores de línguas (estrangeiras) serão abordados nesse sentido. Quanto à questão da identidade, apresento a concepção de aprendizes e professores de Inglês como Língua Estrangeira sobre competência comunicativa e analiso as representações e posições identitárias desses sujeitos enquanto aprendizes e professores de língua estrangeira. A base teórica apóia-se na extensa discussão sobre formação de professores, visando à prática crítico-reflexiva para o ensino de línguas, nos pressupostos sócio-interacionistas/construtivistas vigotskianos e nas atuais investigações sobre representação e identidade de aprendizes e professores de Língua Inglesa. O presente estudo justifica-se principalmente pela crítica que faz à formação de meros reprodutores de técnicas de ensino, priorizando a formação reflexiva de professores de línguas.

\section{INTRODUÇÃO}

Pesquisas sobre formação de professores de línguas têm demonstrado certo despreparo desses profissionais frente à diversidade e complexidade características de contextos de atuação atuais. Resultado de uma concepção epistemológica de ensino, a formação de profissionais técnicos, voltados à solução de problemas práticos e imediatos, através da aplicação de teorias científicas, destacou-se durante o século XX.

Entretanto, este modelo de ensino, que fora imposto pela pedagogia da modernidade, está sendo substituído pelo modelo de formação reflexiva, que permite ao professor aperfeiçoar sua prática, refletindo sobre sua própria ação, por meio da pesquisa - pesquisa-ação. Conseqüentemente, o "professor técnico-especialista" (Gómez, 1992/1995) cede lugar ao professor reflexivo, que participa ativamente de sua formação. 
Considerando, pois, os objetivos deste estudo, busco sustentação teórica nas discussões sobre formação de professores e apresento as influências de três aspectos na formação de futuros professores de línguas estrangeiras, conforme definidos por Vieira-Abrahão (2002: 59): a aprendizagem por meio da observação, o lugar da teoria na formação pré-serviço e a construção da prática pedagógica durante o estágio supervisionado. Concluo esta primeira parte do trabalho, apresentando contribuições da prática reflexiva para a formação de professores de línguas e abordagens para o desenvolvimento de tais práticas durante este processo.

A seguir, investigo as representações de professores e futuros professores de ILE sobre suas identidades profissionais. Baseada nos estudos de Moita Lopes (2002,2002a), Rajagopalan (2002,2003), Grigoletto (2003), entre outros, sobre identidades, especificamente identidade(s) de professores de línguas estrangeiras, neste caso, a Língua Inglesa, apresento a concepção de ambos - alunos e professores - sobre competência comunicativa na língua-alvo. Apresento inclusive as perspectivas desses indivíduos, brasileiros, quanto ao ensino e à aprendizagem do idioma estrangeiro. Finalizo esta segunda etapa, destacando o verdadeiro propósito do ensino de línguas estrangeiras, com base no processo de "redefinição de identidades" (Rajagopalan, 2003: 69). Nas considerações finais, aponto as relações pertinentes entre formação e identidade de professores de línguas (estrangeiras) e algumas conclusões gerais.

\section{TEORIA E PRÁTICA NA FORMAÇÃO DE PROFESSORES DE LÍNGUAS}

Segundo Gómez (1992), há dois modelos de formação de professores, caracterizados por concepções de ensino específicas e divergentes, definidos como racionalidade técnica e racionalidade prática.

O primeiro modelo (racionalidade técnica), devido à dissociação do binômio teoria-prática, inviabiliza a formação de profissionais reflexivos e, conseqüentemente, favorece a formação de verdadeiros técnicos do ensino. Esses profissionais, porque incapazes de refletir sobre seu contexto de atuação, tendo em vista o desenvolvimento de teorias a partir de sua própria prática pedagógica, estão subordinados a técnicas científicas pré-existentes e geralmente inadequadas àquele ambiente. 
A atividade desses professores, segundo Gómez (1992), estaria "dirigida para a solução de problemas mediante a aplicação rigorosa de teorias e técnicas científicas", sendo estas vistas como verdades absolutas. Concluímos, então, que a ênfase na teoria dissociada do conhecimento prático acaba comprometendo a prática docente. Do mesmo modo, a ênfase na prática dissociada da teoria afeta o entendimento do professor no que diz respeito à sua atuação no contexto de sala de aula. Conforme apresenta Magalhães (2002: 42),

Se, por um lado, a ênfase na teoria dissociada da reflexão sobre as práticas discursivas da sala de aula não permite ao professor a compreensão das experiências que efetivamente são criadas nas aulas e os diferentes processos cognitivos que têm lugar durantes as sessões instrucionais, por outro, a ênfase na prática dissociada da teoria deixa o professor sem instrumentos para entender e refletir sobre a sua ação e/ou durante sua ação (Schön, 1985, Kincheloe, 1993).

Das críticas a esse modelo, descrito como incompleto porque, segundo Schön (1983), "ignora as práticas requeridas em situações divergentes", origina-se o modelo da racionalidade prática. Sob essa perspectiva, o professor é visto "como prático autônomo, como artista que reflete, que toma decisões e cria durante a sua própria ação" (Zeichner, 1987). Portanto, verificamos certa preocupação quanto à formação de profissionais reflexivos, que vêem a prática como um meio de construção e não de aplicação de teorias.

No entanto, conforme destaca Vieira-Abrahão (2002), a situação é ainda mais preocupante quando, apesar de ter passado pela universidade e experienciado uma formação pré-serviço "cuidadosa”, o ex-aluno apresenta procedimentos tradicionais de ensino de línguas. Segundo a autora (2002: 59), "a impressão que se tem é que tudo o que foi visto e feito durante sua permanência na universidade não trouxe qualquer modificação ao seu pensar e agir (...)". A fim de identificar as possíveis causas dessa contradição, Vieira-Abrahão discute três aspectos e suas influências na formação de futuros professores de línguas estrangeiras, definidos como: a) a aprendizagem por meio da observação, b) o lugar da teoria na formação pré-serviço e c) a construção da prática pedagógica durante o estágio supervisionado.

O primeiro aspecto, definido como aprendizagem por meio da observação, está relacionado às visões e crenças construídas previamente pelo professor, isto é, ainda na condição de aluno. Este professor, ao ingressar na universidade, já carrega 
consigo concepções sobre o processo de ensinar e aprender uma dada língua estrangeira, construídas ao longo de suas experiências como aprendiz. Wallace (1991 apud Vieira-Abrahão, 2002: 60) define o conjunto de conceitos, crenças, idéias e atitudes como "esquemas conceituais ou construtos", resultantes da exposição voluntária ou involuntária desses indivíduos à prática da profissão, enquanto alunos do ensino fundamental, médio e superior.

A esse respeito, Kennedy (1990 apud Vieira-Abrahão, 2002: 60) afirma que "os professores adquirem marcas aparentemente permanentes de sua experiência como alunos que são difíceis de remover", o que compromete a formação desses indivíduos porque, ao agirem de maneira automática, não refletem sobre as teorias e estratégias apresentadas e, principalmente, sobre a sua própria prática na fase de formação préserviço. Segundo Vieira-Abrahão (2002: 61), “(...) a aprendizagem por meio da observação continua sendo responsável pela perpetuação de modelos e um aspecto dificultador na formação pré-serviço". Nesse sentido, a autora apresenta alternativas eficazes à reflexão e construção de uma base teórica para o aprendiz: a escritura de uma autobiografia associada a perguntas relacionadas à formação do aluno de Letras, aplicadas logo no início do curso de Lingüística Aplicada.

O segundo aspecto, relacionado à função da teoria na formação pré-serviço, refere-se às diferentes concepções de ensino, subjacentes a programas de formação de professores, responsáveis pela definição de procedimentos adotados e enfoque de conteúdo. De acordo com Richards (1998 apud Vieira-Abrahão, 2002: 62), há três concepções: ensino como ciência e pesquisa, ensino como teoria e filosofia e ensino como arte ou artesanato. O que geralmente acontece nos cursos de formação de professores, segundo Vieira-Abrahão, é a eleição de uma única concepção de ensino como correta, sendo as demais consideradas incompatíveis. Nesse momento, constatamos a dissociação entre teoria e prática, dentro do próprio curso. O professor, ao eleger uma concepção de ensino como sendo a única pertinente, está certo de que seus alunos tomarão igualmente partido dela, destituindo-Ihes o direito de descobrir seu próprio estilo de ensinar durante sua experiência didática. Segundo VieiraAbrahão (2002: 65),

O conhecimento é construído por meio da reflexão sobre os problemas reais encontrados e por meio de teorias que se fazem necessárias para a compreensão e busca de soluções. (...) Consideramos necessário que o aluno-professor tenha acesso a teorias e princípios, a resultados e técnicas 
de investigação, a estratégias e técnicas de ensino, mas que os mesmos não sejam apresentados de forma impositiva e dogmática, como verdades únicas e aplicáveis a qualquer contexto.

O terceiro aspecto refere-se à construção da prática pedagógica durante o estágio e envolve uma nova visão dessa prática. Divergente dos conceitos adotados pelos cursos de formação de professores, a prática reflexiva ou ensino reflexivo é enfatizada na década de 90 . Essa concepção, porque destaca o ensino associado à reflexão, representa uma alternativa eficaz à formação e ao desenvolvimento profissional do professor. Segundo essa concepção de ensino, o professor poderá desenvolver-se profissionalmente a partir da reflexão sobre sua própria prática, adotando uma postura crítica em relação ao seu desempenho individual. A autora cita, inclusive, algumas estratégias utilizadas com o propósito de envolver o futuro professor no processo de reflexão sobre a sua prática. Duas estratégias importantes, conforme destaca a autora, seriam: a manutenção de diários reflexivos e o preenchimento de fichas avaliativas. Segundo a Vieira-Abrahão (2002: 71), esse processo pode ser visto como:

(...) um projeto de pesquisa-ação colaborativa, que tem duplo objetivo: propiciar o desenvolvimento profissional do aluno-professor, por meio de um acompanhamento mais próximo e sistemático de sua prática, e analisar como se dá o processo de reflexão na formação pré-serviço do professor de lingua estrangeira.

Conforme dito anteriormente, esses três aspectos, quando adequadamente enfocados nos cursos de formação de professores, contribuem significativamente para a formação de profissionais engajados na prática, responsáveis pelas suas escolhas teóricas e, conseqüentemente, seu desempenho prático enquanto profissionais do ensino.

\subsection{REFLEXÃO E AÇÃO: A QUESTÃO DA PRÁTICA REFLEXIVA}

Considerando a seção anterior, chamo a atenção para duas observações importantes. A primeira, conforme já explicitado, diz respeito à relevância de uma postura reflexivo-crítica na formação de professores de línguas, particularmente, de línguas estrangeiras, sugerindo, conforme destaca Freitas (2002: 79), "um envolvimento investigativo do professor em relação à sua prática e formação, (...)". A 
segunda observação está relacionada à função da reflexão neste processo enquanto "força potencializadora". Freitas, apoiando-se nos estudos de Gebhard (1992), afirma:

\begin{abstract}
Peça chave nesse processo, a reflexão é concebida como uma força potencializadora, entendendo-se que, quanto maior interesse os professores tiverem em se conscientizar do como eles ensinam e quanto mais informados eles se tornarem sobre o que fazem em suas salas de aula e o impacto que isso causa em seus alunos, mais liberdade eles terão de orientar seu próprio ensino em direção a uma aprendizagem bem sucedida do aluno. (Freitas, 2002: 79)
\end{abstract}

Parece-me oportuno acrescentar que o modelo de formação de professores, pautado na racionalidade prática, aborda igualmente os conceitos de reflexão-na-ação e reflexão sobre-a-ação. Schön (1992), buscando a relação entre reflexão e ação, afirma que "o processo de reflexão-na-ação, pode ser desenvolvido numa série de momentos sutilmente combinados numa habilidosa prática de ensino". Dito de outro modo, a reflexão-na-ação consiste no processo de pensar sobre a ação no mesmo momento em que ela ocorre. Por sua vez, a reflexão sobre-a-ação analisa retrospectivamente as ações realizadas e, conforme afirma Schön, define-se como a "análise que o indivíduo faz a posteriori sobre as características e processos da sua própria ação. É a utilização do conhecimento para descrever, analisar e avaliar os vestígios deixados na memória por intervenções anteriores".

Segundo Schön (2000), a formação de profissionais reflexivos está relacionada à idéia de formação de professores capazes de repensar criticamente a sua prática pedagógica, alterando-a conforme os objetivos e as necessidades dos aprendizes. Portanto, a análise crítica do professor a respeito de sua "abordagem de ensinar" seria o primeiro passo para a formação de um profissional reflexivo. Isso porque, ao conscientizar-se sobre a concepção de ensino que adota, o professor estará sujeito a mudanças contínuas de modo que o seu fazer dogmático será gradualmente substituído pelo consciente, isto é, reflexivo (Moita Lopes, 1996). Segundo Jorge (2003: 178), este "percurso" pode ser descrito como "um processo contínuo de autoformação profissional" e pode ser descrito do seguinte modo:

Repensar a abordagem de ensinar é um processo que, em uma perspectiva de educação emancipadora, pode levar a mudanças na abordagem de ensino de professores em formação inicial. Se considerarmos que os alunos de licenciatura encontram-se em processos de formação, parece-nos desejável que sua prática seja constantemente confrontada, questionada e modificada, no processo contínuo de sua educação profissional. Avaliar experiências anteriores, buscar justificar certas ações, interpretar problemas, são ações constituintes da prática reflexiva. 
Vista sob essa perspectiva, a prática do diálogo colaborativo entre professores em formação inicial, na condição de alunos-professores, e o professor formador é um meio bastante viável para a construção do conhecimento. Conforme destaca Verity (2000, apud Jorge, 2003: 179), a respeito da prática do diálogo colaborativo, "percebemos hoje um movimento na área de formação de professores que adota uma perspectiva sociocultural, na qual as práticas de reflexão, auto-avaliação e narrativas ganharam legitimidade".

A prática do diálogo colaborativo remete à teoria sócio-interacionista de Vygotsky, que sustenta que o conhecimento é construído na interação de indivíduos organizados culturalmente. Para elucidar essa constatação, apresento duas passagens retiradas da obra de Jorge (2003), conforme apresentadas por Swain (1995) e Donato (2000), respectivamente:

$\mathrm{Na}$ concepção de Vygotsky, os processos cognitivos surgem da interação entre os indivíduos, de forma que o desenvolvimento cognitivo se dá inicialmente no plano interpsicológico e, por meio de um processo de apropriação, o conhecimento gerado na esfera social passa a ser representado no indivíduo intrapsicologicamente.

Segundo Donato (2000), em referência à teoria de Vygotsky, a linguagem é o principal meio de mediação disponível para os indivíduos engajados na interação social. Assim, a aprendizagem e o desenvolvimento humano estão inerentemente enraizados nas interações sociais.

Portanto, o diálogo colaborativo é visto como uma estratégia para se chegar ao aprendizado. Nas trocas interpessoais, ao discutirem sobre suas experiências, os aprendizes revelam competências e dificuldades, geralmente assimiladas pelo grupo. Metaforicamente, definimos os aprendizes como "andaimes": uns auxiliando aos outros para a construção conjunta do conhecimento. Citando a teoria interacionista, temos que o desenvolvimento cultural do aluno, assim como, sua aprendizagem, dáse mediante o processo de relação do aluno com o professor ou com outros alunos mais competentes. Logo, verificamos uma estreita relação entre os princípios da teoria sócio-interacionista e a prática do diálogo colaborativo como uma estratégia de reflexão, utilizada pelo aluno-professor, para o aprimoramento de sua ação pedagógica. 


\subsection{O SÓCIO-INTERACIONISMO VIGOTSKIANO E A IMPORTÂNCIA DA REFLEXÃO CRÍTICA PARA O ENSINO}

Considerando que, segundo Gómez (1992), o modelo de formação de professores, definido como racionalidade técnica, forma reprodutores de teorias e técnicas, incapazes de refletir sobre sua própria prática, concluímos que esses profissionais encontram-se despreparados para o ensino reflexivo. Embora temos observado mudanças significativas nos cursos de Letras, principalmente a partir da década de 70 , com o surgimento da abordagem comunicativa, verificamos ainda grande ênfase no método tradicional de ensino de línguas. O professor ainda é autoridade na sala de aula, pois tudo sabe e determina, e a linguagem continua a ser vista e analisada como estrutura. Similarmente, a gramática é apreendida através de regras e exemplos descontextualizados, memorizados pelo aluno e ditados pelo professor.

A teoria sócio-interacionista de Vygotsky salienta, entretanto, que a aprendizagem dos alunos vai sendo construída mediante processos de interação entre o indivíduo, seu ambiente sócio-cultural e outros indivíduos mais experientes, construtiva e colaborativamente. Sob essa perspectiva, torna-se nítida a oposição entre a abordagem tradicional de ensino e a teoria sócio-histórica, também conhecida como abordagem sócio-interacionista/construtivista. Portanto, ao contrário do que propõe o método tradicional, a teoria construtivista destina ao professor a função de agente mediador que, por meio da linguagem, intervém e auxilia na construção e reelaboração do conhecimento do aluno, contribuindo para o desenvolvimento deste. Nesse sentido, verificamos a contribuição expressiva de Vygotsky ao elaborar uma metodologia inovativa. Conforme destaca Uchôa (2001),

Piaget e Vygotsky contribuíram para a elaboração de metodologias inovativas que ultrapassam aquelas existentes na escola tradicional. É graças às implicações teóricas destes psicólogos que se pode hoje trabalhar visando a ultrapassar a metodologia pedagógica arraigada na repetição de conceitos. O que tem encorajado inúmeros educadores a inovarem sua prática pedagógica, no sentido de buscar compreender a realidade de seus alunos tanto do ponto de vista psicológico, cognitivo, afetivo, como sócio-cultural. Isto para que, a partir daí, possam trabalhar rumo a uma educação significativa e construtiva - a qual possa conduzir o aluno a ser sujeito consciente de sua autonomia social.

Concluímos, pois, que a tomada de uma postura crítica pelo professor representaria uma alternativa bastante eficaz à solução de vários problemas hoje 
existentes nas escolas. Castro (1999), do mesmo modo que Liberali (1996), afirma que a reflexão crítica é duplamente importante. Primeiro, porque através dela, o professor terá uma visão mais consciente quanto à sua prática, podendo inclusive transformá-la durante este processo. Segundo, porque apresenta efeitos significativos, não apenas no contexto escolar, mas na sociedade como um todo. Do mesmo modo, Magalhães (2000) acredita que a tomada de uma postura crítica seja a solução para vários problemas escolares. Por meio da prática reflexiva, o "educador" poderá repensar o ensino de línguas e sua contribuição neste processo enquanto profissional crítico. Por outro lado, a ausência de reflexão durante o processo impede a conscientização desse professor quanto a mudanças necessárias. Logo, para que o sócio-interacionismo vigotskiano substitua enfoques tradicionais de ensino é preciso, primeiramente, que o professor reflita criticamente sobre seu desempenho enquanto mediador na aquisição do conhecimento. Sobre essa questão, cito Freire (1996: 43), que considera a reflexão crítica sobre a prática de suma importância à formação de professores e afirma:

A prática docente crítica, implicante do pensar certo, envolve o movimento dinâmico, dialético, entre o fazer e o pensar sobre o fazer (...). Por isso, é fundamental na prática da formação docente, que o aprendiz de educador assuma que o indispensável pensar certo não é presente dos deuses nem acha nos guias de professores que iluminados intelectuais escrevem desde o centro do poder, mas, pelo contrário, o pensar certo que supera o ingênuo tem que ser produzido pelo próprio aprendiz em comunhão com o professor formador.

\subsection{ABORDAGENS PARA O DESENVOLVIMENTO DE PRÁTICAS REFLEXIVAS}

Tendo em vista o despreparo de professores de línguas, devido principalmente aos atuais modelos de formação pré-serviço, a busca de novos métodos, destinados à formação de profissionais reflexivos, autônomos e responsáveis, é extremamente relevante neste momento. É preciso, pois, considerarmos novas abordagens para o desenvolvimento de práticas reflexivas. Conforme destaca Jorge (2003: 180),

Nesse processo de reconstrução da profissão, percebemos a questão da reflexão coletiva (através do diálogo colaborativo) como um meio bastante adequado para a formação inicial de professores, visto que a prática de colaboração pode ser um meio eficiente na composição do perfil do profissional que pretendemos formar, capaz de elaborar projetos de trabalho, realizar pesquisas e de administrar a sua própria formação contínua. 
Considerando o exposto, apresento formas de promoção de práticas reflexivas, usadas tanto por alunos-professores quanto por professores-formadores, para discutir individual ou coletivamente sobre sua prática docente. Com base nos textos de Jorge (2003) e Buzzo, Beato e Dalpasquale (2003), apresento as seguintes abordagens para a prática da reflexão crítica:

1) Reflexão escrita;

2) Reflexão em grupo / oral;

3) Gravações em áudio e / ou vídeo;

4) Observação de aulas.

Telles (1999), ao trabalhar com a Pesquisa Narrativa, cita os seguintes instrumentos para uma reflexão crítica: histórias, crônicas, fotografias, entrevistas, diários e autobiografias, memoriais, notas de campo. Sobre a "narrativa" especificamente, busco Wertsch (1998 apud Moita Lopes, 2002a: 65) que a define como "um instrumento cultural de mediação das identidades sociais ou "recursos de identidade". Nesse sentido, verificamos novamente a contribuição de Vygotsky (1978) ao considerar discurso/linguagem como instrumento mediador na construção do conhecimento.

\section{LÍNGUA ESTRANGEIRA E REDEFINIÇÃO DE IDENTIDADES}

Desde o início, o ensino de línguas estrangeiras no contexto brasileiro esteve subordinado a questões políticas, uma vez que apenas uma parcela reduzida da população, aquela pertencente à classe dominante, via-se beneficiada neste sentido. Sob esse aspecto, todo indivíduo que falasse uma língua estrangeira era considerado diferentemente pelos demais, porque tido como culto, portanto, digno de respeito e admiração. Pagel (2002: 23) e Rajagopalan (2003: 65) reiteram essa constatação quando afirmam, respectivamente, que "o domínio de línguas estrangeiras sempre foi privilégio da elite e da classe dominante" e "a língua estrangeira sempre representou prestígio".

Tida como objeto de prestígio e destinada a uma minoria privilegiada, a língua estrangeira passou a ser vista como uma estratégia para a conquista de espaços e 
posição, tanto intelectuais quanto socioeconômicos. Justifica-se, pois, conforme destaca Rajagopalan (2003: 65-70), o fato de professores e pesquisadores raramente questionarem os aprendizes de uma dada língua estrangeira sobre o verdadeiro interesse em aprendê-la. Segundo este autor, há um consenso no sentido de que todo indivíduo que deseja aprender uma língua estrangeira está a procura de oportunidades para melhorar de vida. Torna-se evidente, pois, segundo Rajagopalan (2003: 67), que, ao estudarmos uma língua estrangeira, buscamos uma maneira de "ampliar os nossos horizontes culturais, de nos lançar a um melhor nível de vida - em suma, de tirar proveito do contato com algo previamente entendido e encarado como superior ao que já possuímos", neste caso, nossa língua materna.

Considerando a citação descrita acima, verifica-se certa superioridade do idioma estrangeiro em relação à língua materna dos aprendizes, como se esta fosse incapaz de atender aos interesses comunicativos e pragmáticos de seus usuários. Conseqüentemente, verificou-se uma necessidade imediata por parte de falantes nãonativos em adquirir determinado idioma estrangeiro, conforme seus objetivos. Entretanto, apesar de seus esforços constantes, o falante não-nativo não era reconhecido devido à sua habilidade de expressão em outro idioma que não o seu. Antes, era desprestigiado e considerado incapaz de adquirir a proficiência comunicativa do nativo, cuja competência era definida como perfeita.

Segundo o autor (2003: 68), portanto, "a língua estrangeira e a cultura que a sustenta sempre foram apresentadas como superiores às dos discentes". Devido a isso, o ensino de línguas estrangeiras, durante muito tempo, teve como propósito a imitação do desempenho lingüístico-discursivo de falantes nativos pelos aprendizes. Ainda hoje, verifica-se certa preocupação quanto ao fator autenticidade, principalmente, no que diz respeito aos materiais didáticos adotados. Tanto aprendizes quanto professores de línguas estrangeiras são afetados pelos sentimentos de inferioridade e incapacidade frente à língua-alvo, como se jamais terão desempenho semelhante ao do falante nativo. Como resultado, ambos — professores e alunos - vêem na imitação uma forma de, pelo menos, aproximar o seu desempenho lingüístico ao do falante nativo.

Grigoletto (2003), em seu texto Um dizer entre fronteiras: o discurso de professores e futuros professores sobre a Língua Inglesa, trata dessa questão quando apresenta uma análise sobre a relação existente entre discurso e identidade de 
professores e futuros professores de ILE, a fim de avaliar que posições identitárias esse sujeito, na qualidade de brasileiro, assume diante da língua estrangeira. Neste texto, a autora destaca quatro domínios discursivos baseados nos depoimentos desses professores. Dentre eles, encontra-se o discurso da perfeição quanto ao desempenho na língua inglesa, que, segundo a autora (2003: 44), "são formulações nas quais o sujeito enuncia a sua ânsia pela perfeição no desempenho em língua inglesa, ideal perseguido mas concebido como difícil ou impossível de alcançar". A título de exemplificação, a autora cita seqüências do discurso dos sujeitos da pesquisa, conforme o que segue:

A3: é/ eu sou meio perfeccionista [risos] é::: é::: há um tempo atrás eu tinha aquela ilusão de que eu queria falar como um nativo / agora eu perdi isso né / isso é impossível / e além disso e além disso eu vou estar perdendo a minha identidade cultural [...]eu tinha essa visão uns três / quatro anos atrás / aí eu comecei a fazer aula com um professor nativo / ele falou / esquece isso que você só vai se frustrar / é bobagem / você não precisa disso

Entretanto, essa situação parece estar mudando. Atualmente, tem-se falado em "línguas francas" como formas de comunicação resultantes do contato entre indivíduos, povos e culturas distintas, devido principalmente a necessidades de tempo e espaço, características do processo de globalização atual. As línguas francas ou mistas, conforme definição de Rajagopalan (2003), são resultado da miscigenação crescente entre povos e culturas. Esse processo de miscigenação também é responsável pela fragmentação de identidades que, constantemente, estão se (re) constituindo. Portanto, segundo o autor (2003: 69),

É por esse motivo que se torna cada vez mais urgente entender o processo de 'ensino-aprendizagem' de uma língua "estrangeira" como parte integrante de um amplo processo de redefinição de identidades. (...) As línguas são a própria expressão das identidades de quem delas se apropria. Logo quem transita entre diversos idiomas está redefinindo sua própria identidade. Dito de outra forma, quem aprende uma língua nova está se redefinindo como uma nova pessoa.

Sob essa perspectiva, o ensino de línguas estrangeiras assume uma segunda conotação. Atualmente, esse processo deve ser visto como uma oportunidade de interação entre indivíduos de diferentes culturas. Dito de outro modo, o ensino de línguas estrangeiras constitui uma etapa para se chegar à "redefinição cultural", permitindo a todo indivíduo envolvido neste processo constituir-se como "cidadão do 
mundo". Obviamente, durante essa interação, há fragmentação e conseqüente reformulação de identidades porque, além da evidente diferença entre culturas e ideologias, a identidade é vista como um processo que vai se transformando, ou seja, o sujeito se constitui de acordo com as suas relações sociais.

Considerando, pois, que o "verdadeiro propósito do ensino de línguas estrangeiras é formar indivíduos capazes de interagir com pessoas de outras culturas e modos de pensar e agir" (Rajagopalan, 2003: 70), não caberia buscarmos no desempenho lingüístico do falante nativo uma fórmula para aprendermos línguas estrangeiras. Seria até ignorância pensarmos desse modo quando estamos cientes de que a sociedade de hoje exige de nós o domínio comunicativo de determinada língua estrangeira. Conforme afirma Pagel (2002: 32),

Para o século que iniciou, o domínio de línguas estrangeiras torna-se uma necessidade incontestável. Nesse sentido, o ensino de várias línguas estrangeiras (...) responderá a uma demanda social assim como a uma necessidade e à vontade política de formação do cidadão num mundo plurilíngüe e muito em breve sem fronteiras.

\section{CONSIDERAÇÕES FINAIS}

Conforme verificamos, os conceitos de reflexão e identidade têm sido discutidos amplamente. As discussões apresentadas sobre reflexão crítica e abordagens de ensino, especialmente a construtivista, são úteis à compreensão da reformulação da identidade de professores de ILE. A título de conclusão, apresento agora três considerações importantes. Em primeiro lugar, apoiando-me na literatura sobre formação (pré-serviço) de professores de línguas, considero a prática reflexiva e a participação crítica como responsáveis pela profissionalização desses indivíduos, pois "só por meio da prática reflexiva o professor poderá alcançar o domínio da complexidade e da imprevisibilidade, que é o que encontrará no mundo, na escola, na sala de aula" (Celani, 2001: 15). Em segundo lugar, a aquisição de uma língua estrangeira por falantes não-nativos, neste caso, a Língua Inglesa sendo aprendida por brasileiros, usuários da Língua Portuguesa, deve ser vista como uma oportunidade de interação entre indivíduos de culturas e contextos sociais distintos. A "imitação" de hábitos lingüísticos de falantes nativos deve ser evitada porque não garante a interação entre os indivíduos. Ao contrário, na ânsia de desenvolver uma performance comunicativa idêntica à do nativo, o aprendiz provavelmente terá dificuldades de 
aquisição da língua-alvo, comprometendo, deste modo, sua capacidade comunicativa. Por fim, devo dizer que uma postura crítico-reflexiva por parte do professor (e dos aprendizes) em relação ao ensino e à aprendizagem de línguas estrangeiras contribui para a formação de cidadãos conscientes quanto ao verdadeiro propósito de se aprender uma língua estrangeira: viabilizar a interação de indivíduos com outras culturas, permitindo-Ihes agir e pensar diferentemente, de acordo com contextos de atuação específicos.

\section{BIBLIOGRAFIA}

BUZZO, A. M., BEATO, A. P. M., DALPASQUALE, M. D. (2003). Discutindo condutas investigativas na prática do professor de Lingua Estrangeira. In: GIMENEZ, T. (org.). Ensinando e aprendendo Inglês na universidade: formação de professores em tempos de mudança. Londrina: ABRAPUI.

CASTRO, S. T. R. (1999). A linguagem e o processo de construção do conhecimento: subsídios para a formação do professor de Inglês. Tese de Doutorado. São Paulo: PUC/SP.

CELANI, M. A. A. (1996) O perfil do educador do ensino de línguas: o que muda?Comunicação apresentada em mesa-redonda no I Encontro Nacional de Políticas de Ensino de Línguas Estrangeiras, Universidade Federal de Santa Catarina, Florianópolis.

(1999) "You've snatched the carpet from my under feet": courses as contexts for change in in-service language teacher education". Trabalho apresentado em conferência plenária no Congresso da AILA, Tóquio.

. (2001). Ensino de Línguas Estrangeiras: Ocupação ou Profissão? In:LEFFA, V. (org.) O professor de Línguas Estrangeiras. Construindo a Profissão.Pelotas, EDUCAT.

. (2002). Culturas de Aprendizagem: Risco, Incerteza e Educação. In:MAGALHÃES, M. C. C. (org.) A Formação do professor como um profissional reflexivo: linguagem e reflexão. Campinas. Mercado de Letras.

CELANI, M. A. A., MAGALHÃES, M. C. C. (2002). Representações de professores de Inglês como Língua Estrangeira sobre suas identidades profissionais: uma proposta de reconstrução. In: MOITA LOPES, L. P. da., BASTOS, L. C.

(orgs.). Identidades: recortes multi e interdisciplinares. Campinas: Mercado de Letras.

DONATO, R. (2000). Sociocultural contributions to understanding the foreign and second language classroom. In: LANTOLF, J. P. Sociocultural theories and second language learning. Oxford: Oxford University Press. 
FREIRE, P. (1972/1987). Pedagogia do Oprimido. Paz e Terra.

(1996). Pedagogia da Autonomia: Saberes Necessários à Prática

Educativa. São Paulo: Paz e Terra.

FREITAS, M. A. de. (2002). O movimento reflexivo subjacente a procedimentos de investigação da própria prática pelo professor de língua estrangeira. In: GIMENEZ, T. (org.). Trajetórias na formação de professores de línguas. Londrina: Editora UEL.

GEBHARD, J. G. (1992). Awareness of Teaching: Approaches, Benefits, Tasks. English Teaching Forum, v. 30, n.4, p. 2-7.

GÓMEZ, A. P. (1992/1995). Novos caminhos para o practicum. In: NÓVOA, Antônio. (coord.). Os professores e sua formação. Lisboa: Publicações Dom Quixote, pp. $93-114$.

GRIGOLETTO, M. (2003). Um dizer entre fronteiras: o discurso de professores e futuros professores sobre a Língua Inglesa. Trabalhos em Lingüística Aplicada. Campinas, (41): 41: 39-50, Jan/Jun.

JORGE, M. L. dos Santos. (2003). O diálogo colaborativo e a reflexão crítica na formação de professores de Inglês. In: GIMENEZ, T. (org.). Ensinando e aprendendo Inglês na universidade: formação de professores em tempos de mudança. Londrina: ABRAPUI.

KENNEDY, M. (1990). Policy Issues in Teacher Education. East Lansing, Mich: National Center for Research on Teacher Learning.

LIBERALI, F. C. (1996). O Desenvolvimento Reflexivo do Professor. The ESPecialist, v. 17.1, pp. 19-37.

de Doutorado. PUC/SP.

(1999). O Diário como Ferramenta para a Reflexão Crítica. Tese

MAGALHÃES, M. C. C. (1997). O professor de línguas: um profissional reflexivo. Boletim APLIEPAR, ano VIII, 31.

. (2000). O Conceito de Representação. Manuscrito não publicado. . (org.). (2002). A Formação do professor como um profissional

reflexivo: linguagem e reflexão. Campinas. Mercado de Letras.

(2002). O professor de línguas como pesquisador de sua ação: a

pesquisa colaborativa. In: GIMENEZ, T. (org.). Trajetórias na formação de professores de línguas. Londrina: Editora UEL.

MOITA LOPES, L. P. da. (1996). Interação na Sala de Aula de Língua Estrangeira: a Construção do Conhecimento. In: MOITA LOPES, L. P. Oficina de Lingüística Aplicada: a Natureza Social e Educacional dos Processos de Ensino/Aprendizagem de Línguas.Campinas. Mercado de Letras.

(1996). Oficina de lingüística aplicada: a natureza social dos processos de ensino-aprendizagem de línguas. Campinas, SP: Mercado de Letras. 
de Letras.

. (1996). Oficina de Lingüística Aplicada. Campinas. Mercado

MOITA LOPES, L. P. da., BASTOS, L. C. (orgs.). (2002). Identidades: recortes multi e interdisciplinares. Campinas, SP: Mercado de Letras.

MOITA LOPES, L. P. da. (2002a). Identidades Fragmentadas. A construção discursiva de raça, gênero e sexualidade na escola. Campinas: Mercado de Letras.

Mercado de Letras.

(org.). (2003). Discurso de Identidades. Campinas, SP:

NASCIMENTO DE PAULA, M. (2001). Formação de Professores na

Universidade: um espaço em construção. Dissertação de Mestrado. PUC/SP.

OLIVEIRA, A.C.B. (1996) Qual a sua formação, professor? Papirus Editora.

PAGEL, D. (2002). O ensino da língua estrangeira e o contexto

brasileiro. In: COSTA, M. J. D., ZIPSER, M. E., ZANATTA, M. E., MENDES, A. (orgs.). Línguas: ensino e ações.Florianópolis: UFSC/NUSPPLE.

RAJAGOPALAN, K. (2001a). ELT classroom as an arena for identity clashes. In:GRIGOLETTO, M., CARMAGNANI, A. M. G. (eds.). English as a Foreign Language: Identity, Practices, and Textuality. São Paulo, Brazil:

Humanitas.

. (2003). Por uma lingüística crítica: linguagem, identidade e a questão ética. São Paulo: Editora Parábola, 2003.

. (no prelo). Non-native speaker teachers of English and their

anxieties: ingredients for an experiment in action research. In: ILURDA, E.

(org.). Non-native language teachers: empirical perspectives. Editora Kluwer,

Dordrecht.

RICHARDS, J. C. (1990). The dilemma of teacher education in second language teaching. In: RICHARDS, J. C. E NUNAN, D. (Ed.). Second Language Teacher Education.Cambridge: Cambridge University Press.

SCHÖN, D. A. (1983). The reflective Practitioner. London: Temple Smith. . (1987). Educating the Reflective Practioner. New York: Collier

Books.

(1992/1995) Formar professores como profissionais

reflexivos. In: NÓVOA, Antônio.(coord.). Os professores e sua formação. Lisboa: Publicações Dom Quixote.

- (2000). Educando o profissional reflexivo - um novo desafio para

a aprendizagem. Trad. Roberto Cataldo da Costa - Porto Alegre, RS: Artes Médicas Sul.

SWAIN, M. Collaborative Dialogue: The contribution to Second Language Learning.Plenary paper presented at the Annual AAAL Conference, Long Beach, California, March, 1985. 
TELLES, J. A. (1999). A trajetória narrativa: histórias sobre a formação do professor de línguas e sua prática pedagógica. Trabalhos em Lingüística

Aplicada. Campinas, (34):79-92, jul./dez.

VERITY, D. P. (2000). Side affects: the strategic development of professional satisfation. In:LANTOLF, J. P. Sociocultural theories and second language learning. Oxford: Oxford University Press.

VIEIRA-ABRAHÃO, M. H. (1992). Prática de Ensino e o Estágio Supervisionado como Foco de Pesquisa na Formação do Professor de LE. Contexturas: Ensino Crítico de Língua Estrangeira. (1): 49-54.

. (1996) Conflitos e Incertezas do Professor de Língua

Estrangeira na Renovação de sua Prática de Sala de Aula. Tese de Doutorado. UNICAMP.

. (2002). Teoria e prática na formação pré-serviço do professor de língua estrangeira. In: GIMENEZ, T. (org.). Trajetórias na formação de professores de línguas. Londrina: Editora UEL.

VYGOTSKY, L. S. (1930). Interaction between learning and development. In: M. COLE, V. JOHN-STEINER, S. SCRIBNER e E. SOUBERMAN (orgs.). Mind in society. Cambridge. Cambridge University Press. (1978).

(1987).

. (1934). Pensamento e Linguagem. São Paulo: Martins Fontes,

. (1978). Mind in Society. Londres: Harvard University Press.

WALLACE, M. (1991). Training Foreign Language Teachers: a reflective approach.Cambridge: Cambridge University Press.

WERTSCH, J. (1998). Vygotsky and Bakhtin on community. Department of Education, Washington University, mimeo.

ZEICHNER, K. M.; LISTON, D. P. (1987). Teaching Student Teachers to Reflect. Harvard Educational Review, v. 57, n.1, p. 23-48.

ZEICHNER, K. M. (1992/1995). Novos caminhos para o practicum. In: NÓVOA, Antônio. (coord.). Os professores e sua formação. Lisboa: Publicações Dom Quixote.

LOPES, M. A. B. A análise do discurso do professor: um instrumento para reflexão.lael.pucsp.br/intercambio/06brandaolopes.ps.pdf. Disponível em dez./03.

UCHÔA, K. C. A. (2001). Construtivismo em

Vygotsky.http://www.comp.ufla.br/ kacilene/educacao/vygotsky.html. Disponível em dez./03. 